\title{
Early renal transplant dysfunction due to arterial kinking stenosis
}

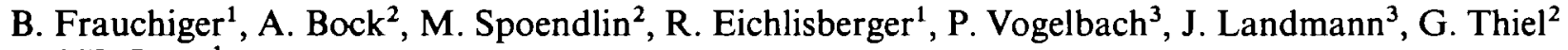 \\ and $\mathrm{K}$. Jäger ${ }^{1}$ \\ ${ }^{1}$ Division of Angiology, ${ }^{2}$ Division of Nephrology, ${ }^{3}$ Division of Vascular Surgery and Transplantation, Unıversity Hospital, \\ Basel, Switzerland
}

\section{Introduction}

The main differential diagnoses of early renal transplant dysfunction include ischaemic damage, cyclosporin toxicity, and rejection [1]. Rarer causes include bleeding, ureteral obstruction, urinary leak, venous thrombosis, and stenosis or occlusion of the renal transplant artery [2]. Early arterial stenosis usually occurs at the site of the anastomosis as a result of too narrow a connection or formation of an intimal crest [3]. Kinking of the transplant artery has rarely been reported as a cause of arterial stenosis. An overview of the reported cases of kinking stenosis found in Medline since 1966 is given in Table 1. None of these reports refer to early graft dysfunction due to kinking stenosis. We report on two patients who developed this complication after living related kidney transplantation. In both cases arterial kinking was diagnosed by duplex sonography and successfully repaired surgically.

\section{Case reports}

Case 1; PP; female; 22 years

This patient had been on chronic haemodialysis from November 1991 because of biopsy-proven type I mem- branoproliferative glomerulonephritis. On 5 December 1991 she was transplanted with the left kidney of her healthy 48-year-old mother. The graft was placed in the right iliac fossa and connected with end-to-side anastomoses to the external iliac vessels. Urine flow from the graft was ensured by an exterior Websinger catheter stenting the ureterocystoneostomy. Immunosuppressive therapy was started with azathioprine the day before transplantation, steroids and OKT3 (5 mg/day for 7 days) at transplantation, and cyclosporin A from day 4 after transplantation.

Although the operation had been completely uneventful, the patient remained anuric postoperatively and serum creatinine failed to decrease. Urinary obstruction was ruled out by several ultrasound examinations, and the Websinger catheter was repeatedly flushed; frusemide had no effect. Haemodialysıs was required on days 2,5 and 7 after transplantation. A very soft systolic bruit was heard over the graft. Renal perfusion scintigrams on days 4 and 5 showed good graft perfusion. Duplex scans (Ultramark 9, ATL, Seattle, USA) were performed according to directions in the literature $[6,9,10]$ on days 1 and 6 . The first examination showed a marked increase in flow velocity in the area of the arterial anastomosis (Figure 1). Intrarenal blood flow was weak and the Doppler signal

Table 1. Reports concerning renal transplant artery kınkıng stenoses in Medlıne 1966-1993

\begin{tabular}{llll}
\hline Author & $\begin{array}{l}\text { Total number of } \\
\text { arterial stenoses }\end{array}$ & $\begin{array}{l}\text { Number of kınkıng } \\
\text { stenoses (\%) }\end{array}$ & $\begin{array}{l}\text { Early postoperative } \\
\text { dysfunction }\end{array}$ \\
\hline Lerf et al 1976 [4] & 10 & $4(40)$ & - \\
Ricotta et al 1978 [5] & 16 & $7(44)$ & - \\
Taylor et al 1987 [6] & 6 & $1(17)$ & $\mathrm{n} \mathrm{r}$ \\
Gross-Fengels et al. & 14 & $1(7)$ & $\mathrm{n} \mathrm{r}$ \\
1988 [7] & 138 & $4(3)$ & - \\
Benoit et al. $1990[8]$ & 20 & $7(2$ of them high & 2 \\
Frauchiger et al & & grade) (35) & \\
$1993\left(^{*}\right)$ & &
\end{tabular}

n $\mathbf{r}=$ Not reported

$(*)=$ Report in preparation

Correspondence and offprınt requests to $\mathrm{Dr} \mathrm{K}$. Jäger, University

Hospital, CH-4031 Basel, Switzerland 


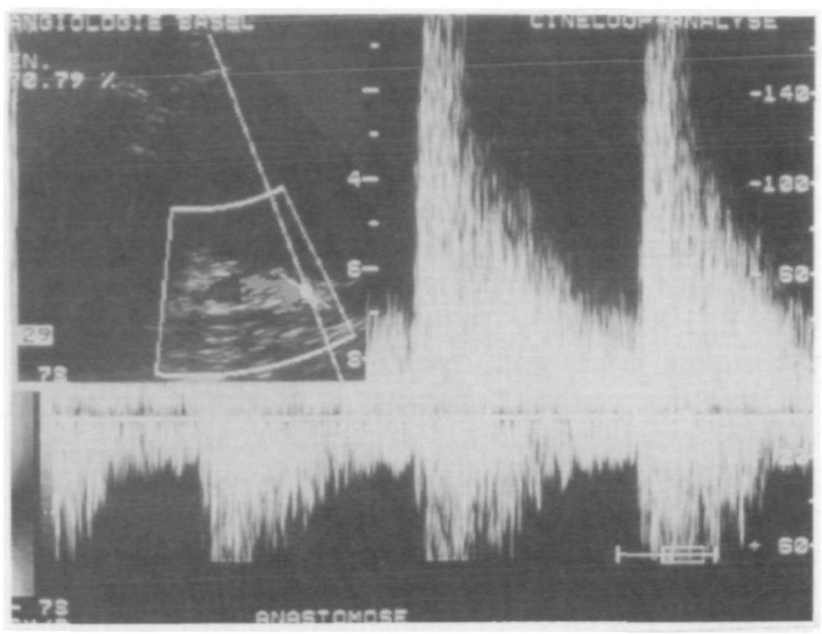

Fig. 1. Duplex-sonogram on the first p.o day of case 1. The left upper part of the dlustration shows the position of the Doppler sample volume in the proximal renal arerty close to the anastomosis On the nght side the Doppler spectral analysis shows a marked increase in systolic velocity of more than $180 \mathrm{~cm} / \mathrm{s}$, combined with turbulence. The findings are compatible with significant stenosis

showed a poststenotic pattern with a delayed systolic increase. A repeat Duplex sonogram on day 6 demonstrated clear evidence of severe stenosis in the area of the anastomosis, which was confirmed by subsequent angiogram (Figure 2).

Surgical revision on December 14 (day 7) revealed a perfused, but only weakly pulsating graft; the graft artery was kınked. Intraoperative Doppler sonography showed a high-frequency signal immediately distal to the anastomosis. The anastomosis itself had a normal flow signal. When the kıdney was lifted slightly and displaced medially, an immediate increase in pulsatility was noted and the pathological Doppler signal disappeared. Therefore the anastomosis was not reopened, and a medial nephropexy was performed. Intraoperative angiography confirmed normalızation of renal perfusion.

Postoperative diuresis ensued after a few hours. A

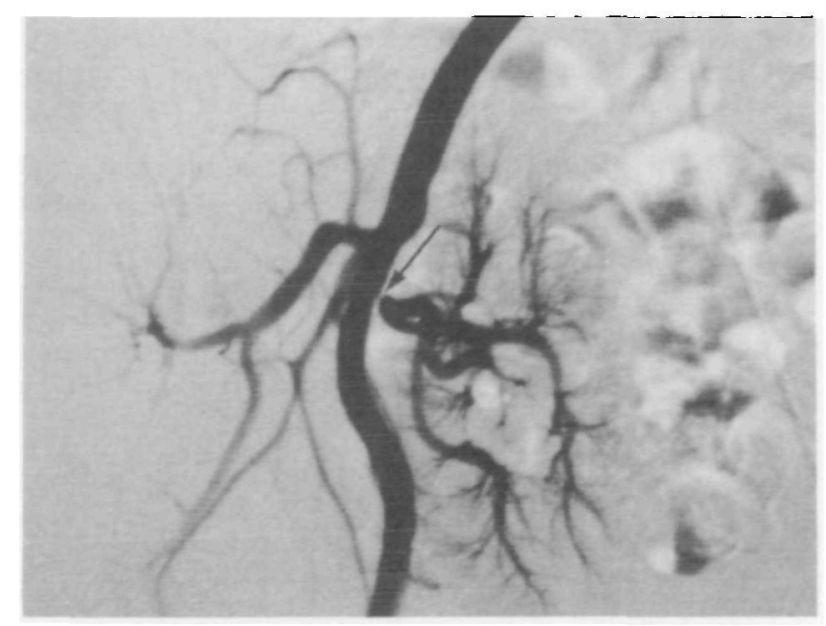

Fig. 2. Angiogram of case 1 on day 6 The arrow marks the filiform stenosis of the renal artery close to the anastomosis duplex sonogram on the next day showed only minimal turbulence in the formerly stenosed region. Signals derived from the segmental renal arteries at this time demonstrated a strong systolic flow and virtually absent diastolic flow. During the next days, polyuria developed and serum creatinine slowly decreased. A duplex sonogram on day 14 was essentially normal. Seven months after transplantation the patient is in excellent health with a creatinine of $100 \mu \mathrm{mol} / 1$ on cyclosporin monotherapy.

\section{Case 2; GA; male, 16 years}

This young patient had been on haemodialysis from May 1992 because of hereditary Alport's nephritis. On 6 June he was transplanted with the left kidney of his healthy 54-year-old father. The graft was placed in the right illac fossa and connected with end-to-side anastomoses to the external iliac vessels. An additional inferior pole artery was connected to the main transplant artery $1.5 \mathrm{~cm}$ distally to the anastomosis. Immunosuppression included azathioprine, antilymphocyte serum, steroids, and cyclosporin A.

Similar to case 1 , this patient remained oliguric during the first postoperatıve day with several hours of complete anuria despite adequate blood pressure and central venous pressure. There was no response to furosemide. Postrenal obstruction was excluded by conventional ultrasound. There was a soft systolic bruit over the transplanted kidney. A duplex ultrasound on day 1 showed an increase of systolic peak velocity up to $400 \mathrm{~cm} / \mathrm{s}$ (normal $<100 \mathrm{~cm} / \mathrm{s}$ ) directly distal to the anastomosis and a poststenotic flow pattern in the peripheral vessels. An artenogram confirmed the severe stenosis distal to the transplant anastomosis, consistent with a 'kinking' stenosis.

The graft was surgically revised $30 \mathrm{~h}$ after transplantation. On open examination the graft was perfused but pulsated only weakly. The artery was kinked close to the anastomosis and intraoperative Doppler demonstrated a stenotic signal at the site of the kinking. By slightly liftıng and medially displacing the kidney, pulsation immediately increased. Medial nephropexy was performed. Soon after repositioning the graft, diuresis resumed and creatinine began to decrease. Duplex sonograms on days 1,5 , and 9 after nephropexy demonstrated residual turbulence distal to the anastomosis with nearly normal flow velocity and normal peripheral flow pattern. The patient was discharged on day 21 with a stable creatinine of $130 \mu \mathrm{mol} / 1$.

\section{Discussion}

Transplant artery stenosis is the most frequent vascular complication after renal transplantation. With a reported incidence between 1 and $15 \%[11-16]$ it is generally considered as a late vascular complication which usually occurs weeks or months after transplantation. Causes include damage to the arterial intima during preparation of the graft, too narrow an 
anastomosis, arteriosclerosis of the donor or recipient vessel, idiopathic fibrosis or fibrin deposits within the context of vascular rejection [15]. The leading clinical symptom is arterial hypertension [17-19]. The 'kinking' type of stenosis differs from the above forms, since it is not the consequence of slowly progressive luminal narrowing but results from an immediate intraoperative or postoperative kinking by malposition of the graft. There are only few published reports on this type of stenosis (Table 1). In all reports, grafts functioned well initially. We assume that these stenoses may be secondary to wall damage by the turbulence of blood flow at the site of kinking. Contrasting with these reports, in the present cases the luminal narrowing was clearly present from the time of operation and critically impaired renal function.

In cadaver kidneys kinking of the renal artery appears to be more common in the kidney from the donor's right side, since the right renal vein is much shorter than the artery and therefore may twist the artery if inappropriately placed [20]. Although the kidneys of the two present cases were taken from living donors' left sides, we suspect that the lack of aortic and caval patches and therefore shorter length of both artery and vein may have been relevant. Both individuals were very slim and we assume that the combination of a relative short artery and compression by fairly tight abdominal wall muscles may have contributed. Furthermore, the location of the arterial anastomosis in relation to the venous anastomosis on the iliac vessels is of critical importance.

This complication seems to be rare, but it needs to be kept in mind, since the remedy is essentially simple. The suspicion should arise when early oliguria, which is unusual in living related kıdney transplants, coincides with the presence of an arterial bruit over the graft. The diagnostic procedure of choice is duplex sonography, which provides both morphological and haemodynamic information. Its value in differentiating ischaemic tubular necrosis from rejection or cyclosporin A toxicity has been questioned [21-23], but its sensitivity and specificity for detecting vascular complications is impressively high $[6,16,24]$. In addition, it is non-invasive and may easily be carried out in the immediate postoperative period. Even if haematoma or superposition of gas make the examination technically more difficult, functional and morphological characterization of parenchyma and vasculature is usually still possible. The paramount finding is an increase of more than 3.5 times in peak systolic velocity within the suspected stenosis when compared to the iliac artery $[9,25]$. The poststenotic signal typically shows a slow systolic rise and a relatively high diastolic flow rate. Since the site of the kink may be immediately adjacent to the anastomosis, differentiation from a stenosis at the anastomosis itself may be difficult. Therefore angiography may be helpful in differentiating the two conditions as illustrated by the two present cases. However, surgical revision seems indicated in both conditions.

Simple nephropexy without opening the renal artery was sufficient in the two reported cases. Assisted by intraoperative Doppler, the graft was displaced medially until the high-pitched stenotic signal disappeared, obviating the need for reopening the graft artery and anastomosis.

The true incidence of kinking stenoses may have been underestimated until now. It is probable that a percentage of the reported renal artery thromboses were due to kinking stenoses that were missed in the pre-duplex-sonography era. Future reports will show whether the incidence of this type of stenosis increases with more widespread use of duplex-sonography.

In conclusion, 'kinking' stenosis of the renal transplant artery is a rare but easily correctable cause of early graft dysfunction. If overlooked, the stenosis may be followed by arterial thrombosis and graft loss. Suspicion should arise when early oliguria coincides with a soft bruit over the transplant, particularly in young, slim recipients of a living donor kidney. The diagnosis can readily be made by duplex sonography and confirmed by angiography.

\section{References}

1 Eggers PW Effect of transplantation on the Medicare end-stage renal disease program $N$ Engl $J$ Med 1988; 318: 223-229

2 Belzer F, Glass N, Sollinger H Technical complications after renal transplantation In Morns PJ ed Kidney Transplantation. Principles and Practice W B Saunders, Philadelphia, 1988, $511-532$

3. Chatterjee Satya N Technical complications of renal transplantation In Chatterje Satya $N$ ed. Manual of Renal Transplantation. Springer Verlag, New York, 1979. 140-165

4. Lerf B, Largiader F, Uhlschmid G, Binswanger U, Pouliadis G. Arterial stenoses after kidney transplantation Langenbecks Arch Chir 1976; 343 11-21

5. Ricotta JJ, Schaff HV, Williams GM, Rolley RT, Whelton PK, Harrington DM. Renal artery stenosis following transplantation Etıology, diagnosis and prevention Surgery 1978; 84. 595-602

6 Taylor KJ, Morse SS, Rigsby CM, Bıa M, Schıff M. Vascular complications in renal allografts' detection with duplex Doppler US. Radiology 1987, 162: 31-38

7. Gross-Fengels W, Hesse U, Neufang KF, Grundmann R DSA in the postoperative diagnosis of patients with kidney transplants. Fortschr Geb Rontgenstr Nuklearmed Erganzungsband $1988,149 \cdot 565-570$

8 Benoit G, Moukarzel M, Hiesse C, Verdellı G, Charpentuer B, Fries D Transplant renal artery stenosis: experience and comparative results between surgery and angioplasty. Transplant Int $1990 ; 3 \cdot 137-140$

9. Kohler TR, Zierler RE, Martin RL et al. Non-1nvasive diagnosis of renal artery stenosis by ultrasonic duplex scanning. $J$ Vasc Surg 1986; 4 450-456

10 Hoffmann U, Edwards J, Strandness E et al. Role of duplex scanning for detection of atherosclerouc renal artery disease. Kudney Int 1991; 39 1232-2139

11 Toledo-Pereyra LH, Lederer E, Suku Wad N Transplantation complications. In- Toledo-Pereyra LH, ed. Kidney Transplantation FA Davis, Philadelphia: 1988. 322-353

12. Lindfors O, Laasonen L, Fyhrquist F, Kock B, Lindstrom B. Renal artery stenosis in hypertensive renal transplant recipients. $J$ Urol 1978; 118. 240-243

13 Schacht RA, Martin DG, Karalakulasingam R, Wheeler CS, Lansing A. Renal artery stenosis after renal transplantation $\mathrm{Am}$ $J$ Surg 1976, 653.653-657

14. LaCombe $M$ Arterial stenosis complicating renal allotransplantation in man Ann Surg 1975, 181: 283-288

15. Dickerman RM, Peters PC, Hull AR, Curry TS, Atkins C, Fry 
WJ. Surgical correction of posttransplant renovascular hypertension. Ann Surg 1980, 192: 639-644

16. Snider JF, Hunter DW, Moradian GP, Castaneda G, Zunıga WR, Letourneau JG. Transplant renal artery stenosis evaluation with duplex sonography. Radiology 1989; 172: 1027-1030

17. Bennett WM, McDonald WJ, Lawson RK, Porter GA Posttransplant hypertension: Studies of the cortical blood flow and the renal pressor system Kidney Int 1974; 6: 99-108

18. Smellie WA, Vinik $M$, Hurne DM. Angiographic investıgation of hypertension complicating human renal transplantation. Surg Gynecol Obstet 1969; 128. 963-968

19. Morris PJ, Yadav RV, Kıncard-Smith P et al. Renal artery stenosis in renal transplantation. Med J Aust 1971, 1: 1255-1257

20. Fabian MA, Hernn MK, Baxter J, Ackermann JR Extension of the nght renal vein in cadaveric renal transplants with use of the vena cava and the TA-30 V3 surgical stapler. Surg Gynecol Obstet 1991; 173 233-234
21 Frauchiger B, Eichlisberger R, Bock A el al. Duplex sonography in patients with early renal allograft dysfunction. A prospectuve biopsy-controlled study. (Abstract) Vasa 1992, 21. 444

22. Genkins SM, Sanfiluppo FP, Carroll BA. Duplex Doppler sonography of renal transplants: Lack of sensitivity and specificity in establıshing pathologic diagnosis Am $J$ Roentgenol 1989; 152: 535-539

23. Perrella RR, Duennckx AJ, Tessler FN et al. Evaluation of renal transplant dysfunction by duplex doppler sonography: A prospective study and review of the literature $A m J$ Kldney $D L s$ $1990 ; 15 \cdot 544-550$

24. Frauchiger B, Eichlısberger R, Bock A et al. Vascular findings in renal allograft dysfunction A prospective duplex sonographic study (Abstract) Vasa 1992, 21. 443

25 Avasthi PS, Voyles WF, Greene ER. Noninvasive diagnosis of renal artery stenosis by echo-Doppler velocimetry. Kudney Int $1984 ; 25 \quad 824-829$ 